\title{
Molecular and Virological Investigation of a Focal Chikungunya Outbreak in Northern India
}

\author{
Manisha Soni, Anil Kumar Singh, Shashi Sharma, Ankita Agarwal, Natarajan Gopalan, \\ P. V. Lakshmana Rao, Manmohan Parida, and Paban Kumar Dash
}

Division of Virology, Defence RङD Establishment, Jhansi Road, Gwalior 474002, India

Correspondence should be addressed to Paban Kumar Dash; pabandash@rediffmail.com

Received 21 August 2013; Accepted 8 October 2013

Academic Editors: R. Hasan, A. Manzin, and A. Zakhartchouk

Copyright (C) 2013 Manisha Soni et al. This is an open access article distributed under the Creative Commons Attribution License, which permits unrestricted use, distribution, and reproduction in any medium, provided the original work is properly cited.

Chikungunya (CHIK) fever is one of the most important arboviral infections of medical significance. The objective of the present study is to identify and characterize the etiology of a focal febrile arthritis outbreak from Gwalior, northern India, during October-November 2010. A detailed virological (isolation) and molecular (end-point RT-PCR, quantitative RT-PCR, and nucleotide sequencing) investigation of this outbreak was carried out by collecting and studying 52 clinical samples and 15 mosquito pools from the affected region. The investigation revealed the presence of CHIK viral RNA in $29 \%$ of clinical samples and $13 \%$ mosquito pool by RT-PCR. The quantification of CHIK viral RNA in samples varied from $10^{2.50}$ to $10^{6.67} \mathrm{copies} / \mathrm{mL}$, as demonstrated through quantitative RT-PCR. In addition, six CHIK viruses were isolated from RT-PCR positive samples. The nucleotide sequences of partial E1 gene of five representative CHIK viruses were deciphered, which revealed that all the viral strains from this outbreak belong to the recently emerging ECS African genotype. Identification of Chikungunya virus ECSA African genotype as the etiology of the present outbreak confirms the continued circulation of the novel genotype, since 2006, in India. The identification of CHIK virus in Aedes aegypti also confirmed it as the major vector in northern India.

\section{Introduction}

Chikungunya fever has emerged as one of the most important arboviral infection of public health significance. It is endemic in many parts of Africa and Asia. Since January 2005, many countries in the Indian Ocean and Asia witnessed unparallel Chikungunya outbreaks $[1,2]$. Chikungunya virus (CHIKV), the etiological agent, belongs to the family Togaviridae and the genus Alphavirus. CHIKV is primarily transmitted by Aedes aegypti and Aedes albopictus mosquitoes and is maintained through a man-mosquito-man cycle in nature [3]. Chikungunya infection in human is characterized by abrupt clinical onset, involving fever, headache, fatigue, nausea, myalgia, and severe arthralgia. This is followed by constitutional symptoms that include maculopapular rash on the trunk and limbs. Symptoms are generally self-limiting and can last for around a week, although arthralgia may persist in a small proportion of cases even for months $[4,5]$. However, during recent outbreaks, cases involving unusual manifestations and severities, including neurological complications and mortality, have been widely reported $[1,6]$.
Currently, there is no specific vaccine or antiviral therapeutics available against Chikungunya infection.

The genome of CHIKV consists of a linear, single stranded, positive sense ribonucleic acid (RNA) of approximately $11.7 \mathrm{~kb}$ in length [7]. CHIKV was first isolated from Tanzania, Africa, in 1953. Later, it has caused numerous outbreaks in continental Africa, the Indian Ocean region, and Southeast Asia including India. It was first reported in 1963 from Calcutta. The reemergence of Chikungunya outbreaks is generally unpredictable and occurs frequently after $8-20$ years of silence [8]. The resurgence of Chikungunya after 2005 is considered unprecedented, owing to the geographical expansion and magnitude of morbidity. Chikungunya has resurged in the form of explosive epidemic in India, in 2006, after a gap of 32 years [9]. Since then, the disease continued in many parts of India affecting more than 4 million persons till 2010, causing huge public health concern [10]. Molecular investigation of these outbreaks revealed emergence of a new variant African genotype of CHIKV as the etiology [11-13]. In the present study, we have carried out 


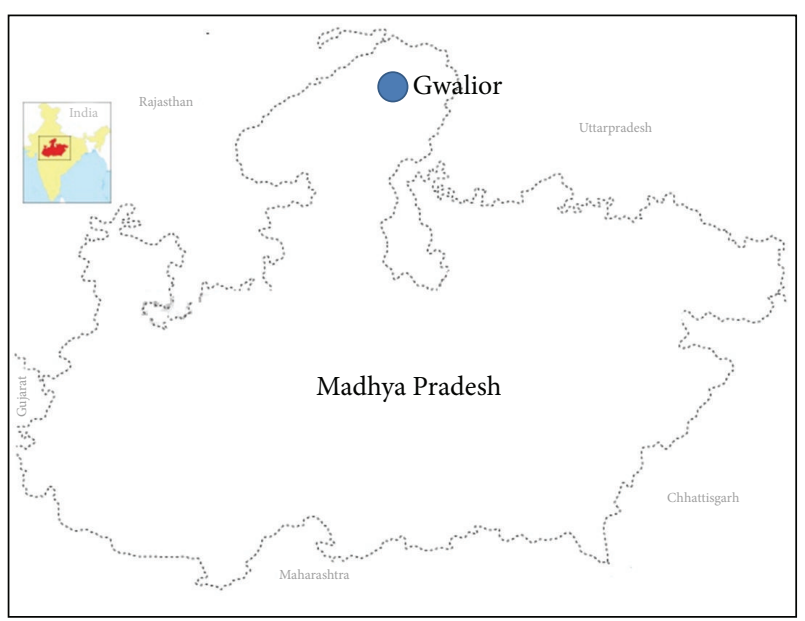

Figure 1: Map of the state of Madhya Pradesh, India, showing the location of Chikungunya affected area.

a detailed molecular investigation by collecting both human and mosquito samples from affected area of Gwalior, Madhya Pradesh, and northern India to identify and characterize the etiology of this focal outbreak during October-November 2010 .

\section{Materials and Methods}

2.1. Clinical Samples. A total of 52 blood samples from clinically suspected Chikungunya patients were collected from G. R. Medical College, Gwalior, Madhya Pradesh and Government PHC, Atri, Gwalior, MP, during OctoberNovember 2010 (Figure 1). Informed consent was obtained from all the patients prior to sample collection. Serum was separated from the blood samples and stored at $-80^{\circ} \mathrm{C}$ till use.

2.2. Mosquito Samples. Fifteen adult Aedes aegypti mosquito pools (size ranging from 8 to 30 ) were collected from eight different locations in the village of Atri, and the city of Gwalior. The adult pools were frozen at $-80^{\circ} \mathrm{C}$ till use.

\subsection{Reverse Transcription-Polymerase Chain Reaction} (RT-PCR). The RNA from serum samples and clarified homogenate of mosquito pools were isolated using QIAamp viral RNA minikit (Qiagen, Germany) in accordance with the manufacturer's instructions. The presence of CHIKV specific RNA was detected using Enhanced Avian HS RT-PCR kit (Sigma, USA) employing a primers pair targeting the E1 gene (CHIK13: TTACATCACGTGCGAATAC genome position 10128-10146 and CHIK14: CTTTGCTCTCAGGCGTGCGACTTT genome position 10604-10627), designed from the nucleotide sequence of the reference S27 strain, GenBank Acc no. AF490259. The thermal profile for RT-PCR was a reverse transcription step at $48^{\circ} \mathrm{C}$ for $45 \mathrm{~min}$ and denaturation at $95^{\circ} \mathrm{C}$ for $3 \mathrm{~min}$, followed by 35 cycles of thermal cycling, which included denaturation at $95^{\circ} \mathrm{C}$ for $1 \mathrm{~min}$, annealing at $55^{\circ} \mathrm{C}$ for $1 \mathrm{~min}$, an extension at $72^{\circ} \mathrm{C}$ for $1 \mathrm{~min}$ and final extension at $72^{\circ} \mathrm{C}$ for 10 minute. The amplicons were verified by $1.5 \%$ standard agarose gel electrophoresis.
2.4. SYBR Green-Based Quantitative RT-PCR ( $q R T-P C R)$. The quantification of Chikungunya viral RNA in clinical samples and mosquitoes was carried out employing a onestep real-time SYBR Green-based qRT-PCR [14]. Briefly, qRT-PCR was carried out in a final volume of $25 \mu \mathrm{L}$ using SuperScript III Platinum SYBR Green One-Step qRT-PCR kit (Invitrogen, USA) containing $12.5 \mu \mathrm{L}$ of $2 \mathrm{X}$ SYBR green reaction mix, $1 \mu \mathrm{L}$ of RT/Taq mix, and $10 \mu \mathrm{mol}$ each of CHIKV specific sense and antisense primers (CK1: ACGCAATTGAGCGAAGCAC and CK2: CTGAAGACATTGGCCCCAC) in Mx3005 instrument (Stratagene, USA). The thermal profile was RT step at $50^{\circ} \mathrm{C}$ for $10 \mathrm{~min}$, followed by holding at $95^{\circ} \mathrm{C}$ for $5 \mathrm{~min}$, and then 40 cycles of denaturation at $95^{\circ} \mathrm{C}$ for $15 \mathrm{~s}$, annealing at $55^{\circ} \mathrm{C}$ for $30 \mathrm{~s}$, and extension at $72^{\circ} \mathrm{C}$ for $30 \mathrm{~s}$. Following amplification, a melting curve analysis was performed to verify the authenticity of the amplification. A standard curve was drawn using 10 -fold serially diluted in vitro transcribed RNA, as described earlier [15]. The RNA copies were determined from the respective $\mathrm{Ct}$ value obtained from the standard curve.

2.5. Virus Isolation. The PCR positive acute phase serum samples and clarified homogenate of mosquito samples were passaged in $\mathrm{C} 6 / 36$ for isolation of the virus. Briefly, culture tubes (Nunc, Denmark) containing preformed monolayer of C6/36 cells were adsorbed with $0.2 \mathrm{~mL}$ of plasma samples (diluted 1:10 in EMEM and filtered through membrane of $0.22 \mu$ pore diameter) for $90 \mathrm{~min}$ at $37^{\circ} \mathrm{C}$ with intermittent shaking. The inoculum was then replenished with $2 \mathrm{~mL}$ of maintenance medium (EMEM with $2 \%$ FBS). Suitable cell controls were also kept alongside. The cells were harvested on appearance of cytopathic effects or on the fourth day after infection (dpi), which ever occurred earlier. Each sample was passaged thrice before declaring as negative. The Identification of the virus isolates obtained from the clinical samples was carried out by RT-PCR.

2.6. Nucleotide Sequencing and Phylogenetic Analysis. Double pass sequencing of five CHIK viruses (four from clinical samples and one from mosquito pools) was carried out with a Big dye terminator cycle sequencing ready reaction kit (Applied Biosystems, USA) on an ABI3130 sequencer following the manufacturer's protocol. Following sequencing, the nucleotide sequences were edited and analyzed with the EditSeq and MegAlign modules of the Lasergene 5 software package (DNAStar Inc., USA). Phylogenetic analysis was conducted using MEGA version 5.03 [16]. Tamura Nei model of nucleotide substitution with gamma-distribution rates available in MEGA was used to construct the NeighborJoining tree. The tree topologies were evaluated using 10000 replicates of the data set.

\section{Results}

3.1. The Epidemic. A focal outbreak of febrile arthritis was reported in Gwalior region of Madhya Pradesh and some other parts in the central India in October-November 2010, affecting a large population in the area. A total of 52 clinical 
TABLE 1: Signs and symptoms of Chikungunya infected patients.

\begin{tabular}{lc}
\hline Sign and symptoms & Number (percentage) of patients \\
\hline Fever & $52(100)$ \\
Joint pain & $42(80)$ \\
Chill & $32(62)$ \\
Headache & $16(30)$ \\
Abdominal pain & $4(7.69)$ \\
Anorexia & $9(17.3)$ \\
Nausea & $6(11.53)$
\end{tabular}

samples were collected from the affected area. The clinical history revealed that all patients had suffered from acute onset of fever with headache and joint pain. Common symptoms were fever with chill, joint pain, and headache. Anorexia, nausea, and abdominal pain were the other associated minor symptoms (Table 1). The majority of the patients have severe joint pain with swelling. The sex ratio of the infected individuals was $3: 2$ (male: female). The maximum individuals infected were found to be in the age group of $24-40$ years.

3.2. RT-PCR. A total of 15 (29\%) clinical samples were found to be positive for the presence of CHIKV specific RNA, through demonstration of CHIKV specific 500 bp amplicons on agarose gel. Similarly, two (13\%) adult Aedes aegypti mosquito pools were found positive for CHIKV RNA.

3.3. SYBR Green-Based Quantitative RT-PCR ( $q R T-P C R$ ). The quantification of CHIKV RNA in clinical samples varied from $10^{2.50}$ to $10^{6.76}$ copies $/ \mathrm{mL}$. The average CHIKV RNA titre in adult Aedes aegypti mosquito pools was $10^{3.09}$ copies $/ \mathrm{mL}$. The result revealed one additional positive sample (DRDE10_GWL9), compared to conventional RTPCR (Table 2).

3.4. Virus Isolation. The three serial passages of 15 RTPCR positive clinical samples resulted in isolation of six CHIKV isolates. Virus isolation was not successful from mosquito samples. The cytopathic effect was characterized by an irregular morphology and foamy degeneration of cells at 3-4 dpi. The mock infected cells remained healthy, with no changes in their cellular morphology. The isolations were also confirmed by RT-PCR.

3.5. Nucleotide Sequencing and Phylogenetic Analysis. The nucleotide sequencing of the partial E1 gene (457 nucleotides) of five CHIKV was determined in this study. These sequences were submitted to GenBank and Accession no. JQ319798JQ319802 was assigned. These sequences were compared with twenty-nine other geographically diverse CHIKV isolates. The alignment did not reveal any nucleotide deletions or insertions. The phylogenetic analysis classified all the $35 \mathrm{CHIKV}$ into three distinct genotypes. The dendogram revealed that all the five CHIKV strains from this outbreak belong to the ECS African genotype (Figure 2). This genotype is represented by large number of recent isolates from $\mathrm{La}$ Reunion (2005-06), Mauritius (2006), Sri Lanka (2008),
TABLE 2: Quantification of Chikungunya viral RNA in clinical samples and mosquito pools by qRT-PCR.

\begin{tabular}{lcc}
\hline Sample ID* & $\begin{array}{c}\text { Quantification of CHIKV } \\
\text { RNA (copies/mL) }\end{array}$ & Ct value \\
\hline DRDE10_GWL1 & $10^{2.644}$ & 28.12 \\
DRDE10_GWL2 & $10^{2.769}$ & 27.72 \\
DRDE10_GWL3 & $10^{2.823}$ & 27.55 \\
DRDE10_GWL4 & $10^{4.332}$ & 22.73 \\
DRDE10_GWL5 & $10^{2.769}$ & 27.72 \\
DRDE10_GWL6 & $10^{2.904}$ & 27.29 \\
DRDE10_GWL7 & $10^{2.863}$ & 27.42 \\
DRDE10_GWL8 & $10^{2.716}$ & 27.89 \\
DRDE10_GWL9 & $10^{2.506}$ & 28.56 \\
DRDE10_GWL10 & $10^{2.819}$ & 27.56 \\
DRDE10_GWL11 & $10^{2.754}$ & 27.77 \\
DRDE10_GWL12 & $10^{6.761}$ & 14.97 \\
DRDE10_GWL13 & $10^{3.712}$ & 24.71 \\
DRDE10_GWL14 & $10^{2.722}$ & 27.87 \\
DRDE10_GWL15 & $10^{5.766}$ & 18.15 \\
DRDE10_GWL16 & $10^{6.492}$ & 15.83 \\
DRDE10_GWL1M & $10^{3.270}$ & 26.12 \\
DRDE10_GWL2M & $10^{2.910}$ & 27.27 \\
\hline
\end{tabular}

${ }^{*}$ The sample ID with a suffix M refers to the mosquito samples.

Singapore (2008), Malaysia (2008), Thailand (2008), Italy (2007), and France (2010), in addition to number of imported cases in Germany (2006), United States (2006), and China (2008). The root of this genotype is represented by older African CHIKV isolates from Tanzania (1953), South Africa (1976), and Uganda (1982). However, the earlier Asian isolates from India, Indonesia, Philippines, and Thailand (1965-1996) were found to belong to the Asian genotype. The CHIKV isolates from Senegal and Nigeria (1964-1983) were grouped into the West African genotype.

\section{Discussion}

Chikungunya has emerged as a major public health problem in many tropical countries of Africa and Asia. Off late, it is considered as a potential threat to even temperate countries in Europe and the Americas [17]. The geographical expansion of Aedes albopictus to temperate zone makes these areas as higher risk. The recent local cases in Italy and France highlighted the epidemic potential of CHIKV in temperate regions $[18,19]$. The explosive reemergence of Chikungunya with more than 4 million cases in India alone since 2006 is an international medical concern. Many Indian states continued to witness the infection and it is also reported from newer geographical area. In addition to the novel African genotype, the lack of herd immunity among population is often cited as the primary reason for its rapid spread across India [14].

The present focal outbreak was reported, during OctoberNovember 2010, in and around Gwalior in northern India. The occurrence of Chikungunya in postmonsoon season is 


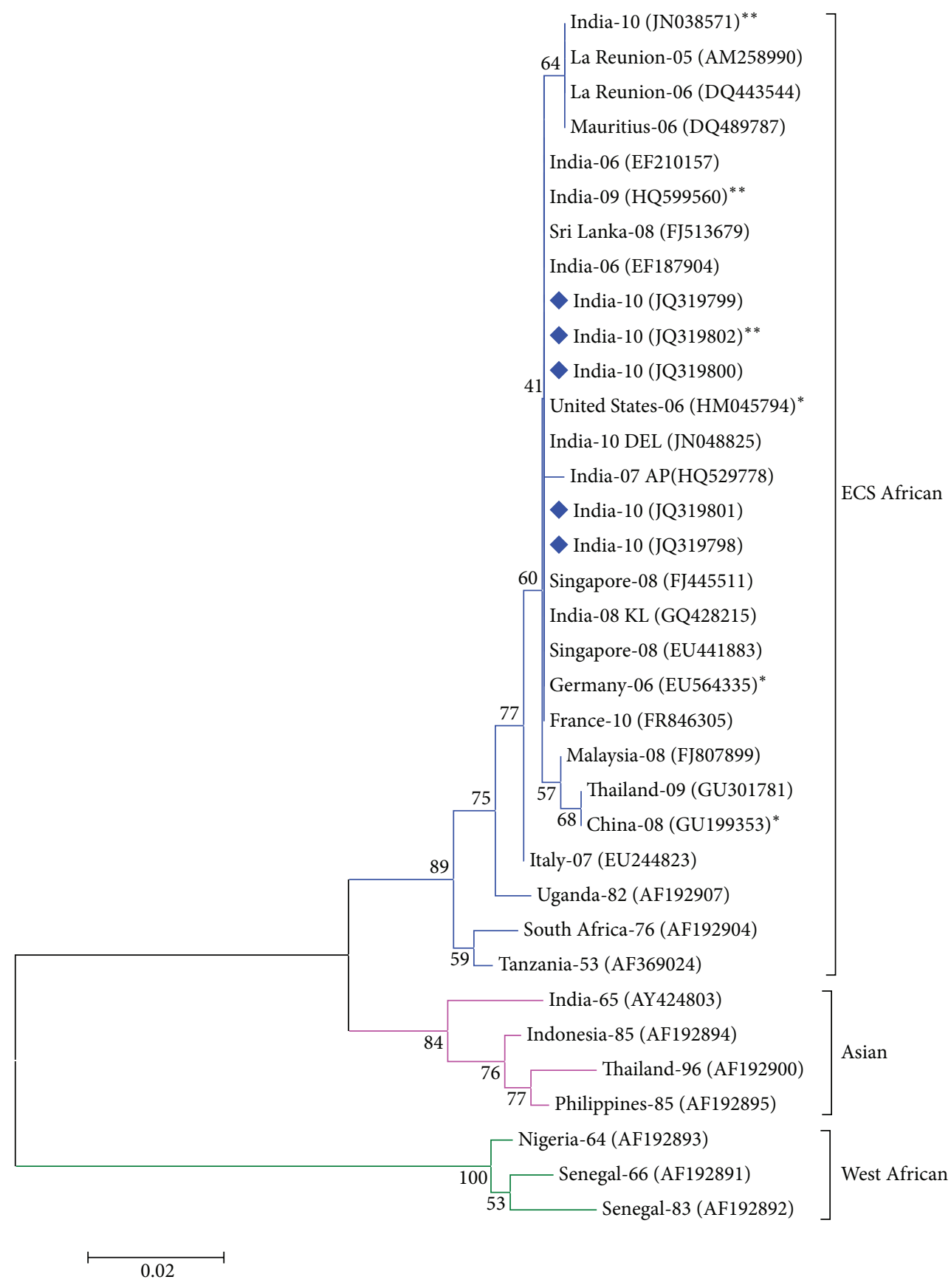

FIGURE 2: Phylogenetic tree among CHIK viruses generated by neighbor-joining method based on the partial nucleotide sequence of E1 gene. Each strain is abbreviated with the country of origin and last two digits of the year of isolation, followed by GenBank accession number in parenthesis (). The CHIKV sequenced in this study are marked with solid diamond $(\bullet)$. Bootstrap values are indicated at the major branch points. ${ }^{*}$ indicates the sequence of CHIKV from imported cases and ${ }^{* *}$ indicates the sequences of CHIKV isolated from mosquito hosts.

also reported from other parts of India [13, 20]. The favorable mosquitogenic condition during postmonsoon period is primarily responsible for the rapid spread of Chikungunya. In spite of extensive attempt to control the mosquito population, it is far from realization.

Historically, the Chikungunya infection was reported to cause primarily mild infections in humans. However, the recent outbreaks witnessed wide array of symptoms among patients with unprecedented morbidity and mortality [1, 21]. A detailed molecular investigation was carried out on the clinical samples and the mosquito pools to ascertain the etiology of the outbreak. The RT-PCR technique has been successfully utilized for confirming Chikungunya in the acute phase of infection. The presence of CHIKV RNA in both clinical and mosquito samples by Chikungunya specific RT-PCR confirmed the etiology. The identification 
of CHIKV in Aedes aegypti pools confirms it as the primary vector of Chikungunya virus in northern India. Subsequently quantitative RT-PCR was carried out to determine the viral load in the samples. The CHIKV RNA load was found to range from $10^{2.50}$ to $10^{6.76}$ copies $/ \mathrm{mL}$. The one additional positive sample in qRT-PCR compared to end-point RT-PCR is due to lower RNA load $\left(10^{2.5}\right.$ copies $\left./ \mathrm{mL}\right)$ in that sample. The higher sensitivity of qRT-PCR over end-point RT-PCR has already been widely reported $[21,22]$. The higher viremia is also responsible for the rapid spread of infection in a community through mosquito vector $[22,23]$.

The phylogenetic analysis clearly classified the CHIKV from the present study to ECSA genotype. It formed a close branch along with large number of recent Indian CHIKV isolates, confirming the continued circulation of ECSA genotype viruses. The ECSA genotype is rapidly spreading in different parts of tropics and replacing the earlier circulating genotypes.

The detailed molecular investigation of both clinical and mosquito samples led to identification of ECSA genotype of CHIKV as the etiology of the present outbreak. This study also confirmed Aedes aegypti as the primary vector of Chikungunya virus in northern India. This ECSA genotype is attributed to prolonged chronic arthritis with fatal outcome on many instances. The recent evidence of rapid adaptation of this virus into mosquito population in temperate region points towards an alarming scenario in future. The persistence of Chikungunya virus and regular occurrence of outbreaks in south Asia is a major cause of concern, which requires continuous monitoring of the viral circulation in both endemic and non-endemic areas.

\section{Ethical Approval}

The study was duly approved by the Ethical Committee of DRDE, Gwalior, India.

\section{Conflict of Interests}

The authors declare that they have no conflict of interests.

\section{Acknowledgments}

The authors are thankful to the Director, DRDE, Gwalior for his keen interest and constant support in this study. The authors are also thankful to the Superintendent, G. R. Medical College, Gwalior, MP, and Government PHC, Atri, Gwalior, MP, for providing the clinical samples. The funding for this work was received from the Defence Research and Development Organization, Government of India.

\section{References}

[1] I. Schuffenecker, I. Iteman, A. Michault et al., "Genome microevolution of Chikungunya viruses causing the Indian Ocean outbreak," PLoS Medicine, vol. 3, no. 7, article e263, 2006.

[2] L. C. Ng and H. C. Hapuarachchi, "Tracing the path of Chikungunya virus-evolution and adaptation," Infection, Genetics and Evolution, vol. 10, no. 7, pp. 876-885, 2010.
[3] M. Vazeille, S. Moutailler, D. Coudrier et al., “Two Chikungunya isolates from the outbreak of La Reunion (Indian Ocean) exhibit different patterns of infection in the mosquito, Aedes albopictus," PLoS ONE, vol. 2, no. 11, Article ID e1168, 2007.

[4] A. M. Powers and C. H. Logue, "Changing patterns of chikunya virus: re-emergence of a zoonotic arbovirus," Journal of General Virology, vol. 88, no. 9, pp. 2363-2377, 2007.

[5] R. N. Charrel, X. de Lamballerie, and D. Raoult, "Chikungunya outbreaks-the globalization of vectorborne diseases," The New England Journal of Medicine, vol. 356, no. 8, pp. 769-771, 2007.

[6] P. Lewthwaite, R. Vasanthapuram, J. C. Osborne et al., "Chikungunya virus and central nervous system infections in children, India," Emerging Infectious Diseases, vol. 15, no. 2, pp. 329-331, 2009.

[7] S. R. Santhosh, P. K. Dash, M. M. Parida, M. Khan, M. Tiwari, and P. V. L. Rao, "Comparative full genome analysis revealed E1: A226V shift in 2007 Indian Chikungunya virus isolates," Virus Research, vol. 135, no. 1, pp. 36-41, 2008.

[8] K. Laras, N. C. Sukri, R. P. Larasati et al., "Tracking the re-emergence of epidemic Chikungunya virus in Indonesia," Transactions of the Royal Society of Tropical Medicine and Hygiene, vol. 99, no. 2, pp. 128-141, 2005.

[9] P. K. Dash, M. M. Parida, S. R. Santhosh et al., "East Central South African genotype as the causative agent in reemergence of Chikungunya outbreak in India," Vector-Borne and Zoonotic Diseases, vol. 7, no. 4, pp. 519-527, 2007.

[10] National Vector borne disease control Programme (NVBDCP), "Chikungunya cases," 2013, http://nvbdcp.gov.in/chik-cd.html.

[11] P. N. Yergolkar, B. V. Tandale, V. A. Arankalle et al., "Chikungunya outbreaks caused by African genotype, India," Emerging Infectious Diseases, vol. 12, no. 10, pp. 1580-1583, 2006.

[12] V. A. Arankalle, S. Shrivastava, S. Cherian et al., "Genetic divergence of Chikungunya viruses in India (1963-2006) with special reference to the 2005-2006 explosive epidemic," Journal of General Virology, vol. 88, no. 7, pp. 1967-1976, 2007.

[13] S. R. Santhosh, P. K. Dash, M. Parida, M. Khan, and P. V. L. Rao, "Appearance of E1: A226V mutant Chikungunya virus in coastal Karnataka, India during 2008 outbreak," Virology Journal, vol. 6, article 172, 2009.

[14] A. B. Sudeep, S. L. Hundekar, P. G. Jacob, R. Balasubramanian, V. A. Arankalle, and A. C. Mishra, "Investigation of a Chikungunya-like illness in Tirunelveli district, Tamil Nadu, India 2009-2010," Tropical Medicine and International Health, vol. 16, no. 5, pp. 585-588, 2011.

[15] P. K. Dash, M. Tiwari, S. R. Santhosh, M. Parida, and P. V. L. Rao, "RNA interference mediated inhibition of Chikungunya virus replication in mammalian cells," Biochemical and Biophysical Research Communications, vol. 376, no. 4, pp. 718-722, 2008.

[16] K. Tamura, D. Peterson, N. Peterson, G. Stecher, M. Nei, and S. Kumar, "MEGA5: molecular evolutionary genetics analysis using maximum likelihood, evolutionary distance, and maximum parsimony methods," Molecular Biology and Evolution, vol. 28, no. 10, pp. 2731-2739, 2011.

[17] V. Sambri, F. Cavrini, G. Rossini, A. Pierro, and M. P. Landini, "The 2007 epidemic outbreak of Chikungunya virus infection in the Romagna region of Italy: a new perspective for the possible diffusion of tropical diseases in temperate areas?" New Microbiologica, vol. 31, no. 3, pp. 303-304, 2008.

[18] G. Rezza, L. Nicoletti, R. Angelini et al., "Infection with Chikungunya virus in Italy: an outbreak in a temperate region," The Lancet, vol. 370, no. 9602, pp. 1840-1846, 2007. 
[19] M. Grandadam, V. Caro, S. Plumet et al., "Chikungunya virus, Southeastern France," Emerging Infectious Diseases, vol. 17, no. 5, pp. 910-913, 2011.

[20] B. Dwibedi, N. Mohapatra, M. K. Beuria et al., "Emergence of Chikungunya virus infection in Orissa, India," Vector-Borne and Zoonotic Diseases, vol. 10, no. 4, pp. 347-354, 2010.

[21] S. R. Santhosh, M. M. Parida, P. K. Dash et al., "Development and evaluation of SYBR Green I-based one-step real-time RTPCR assay for detection and quantification of Chikungunya virus," Journal of Clinical Virology, vol. 39, no. 3, pp. 188-193, 2007.

[22] A. Agarwal, A. K. Singh, S. Sharma et al., "Application of Real-time RT-PCR in vector surveillance and assessment of replication kinetics of an emerging novel ECSA genotype of Chikungunya virus in Aedes aegypti," Journal of Virological Methods, vol. 193, no. 2, pp. 419-425, 2013.

[23] R. S. Lanciotti, O. L. Kosoy, J. J. Laven et al., "Chikungunya virus in US travelers returning from India, 2006," Emerging Infectious Diseases, vol. 13, no. 5, pp. 764-767, 2007. 

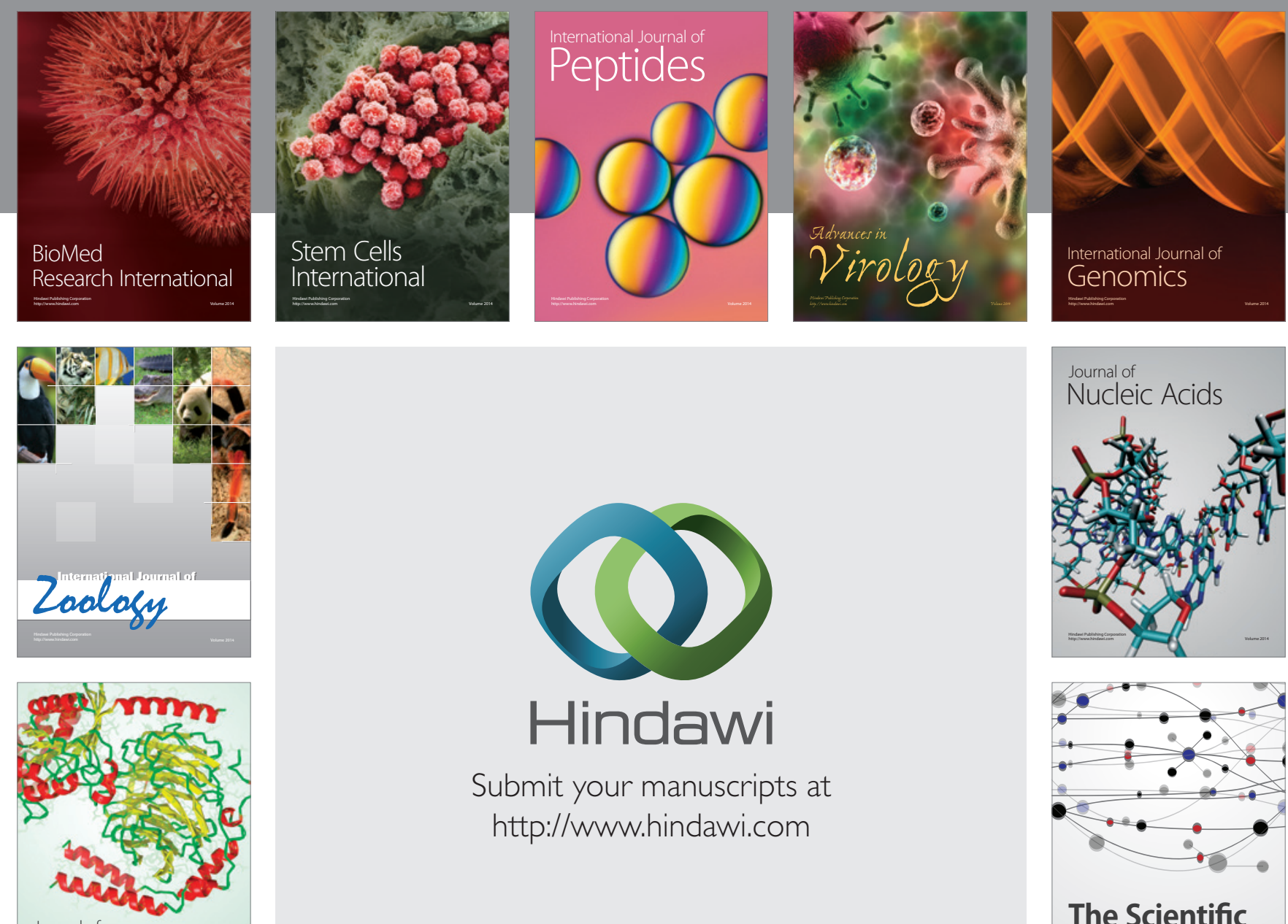

Submit your manuscripts at

http://www.hindawi.com

Journal of
Signal Transduction
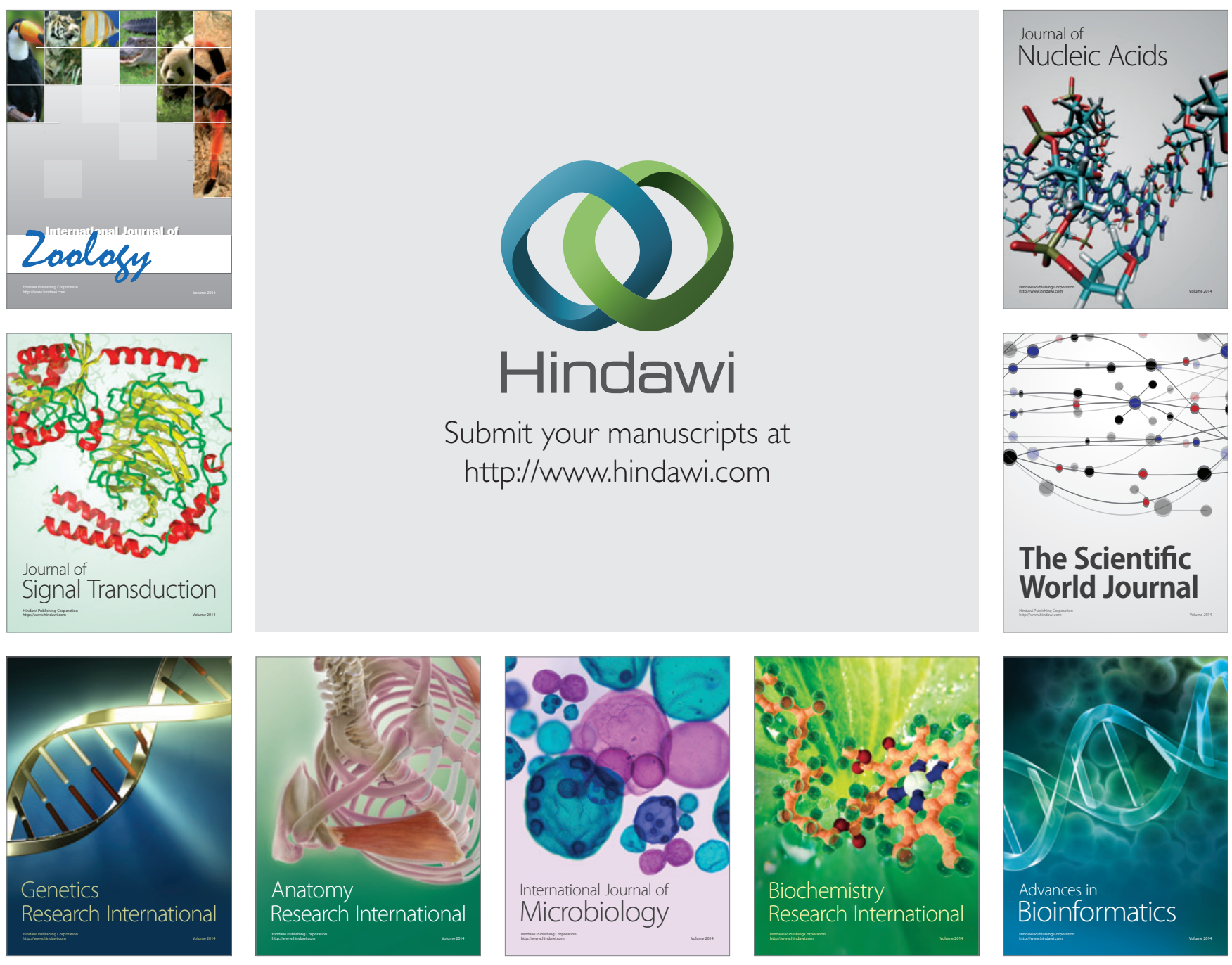

The Scientific World Journal
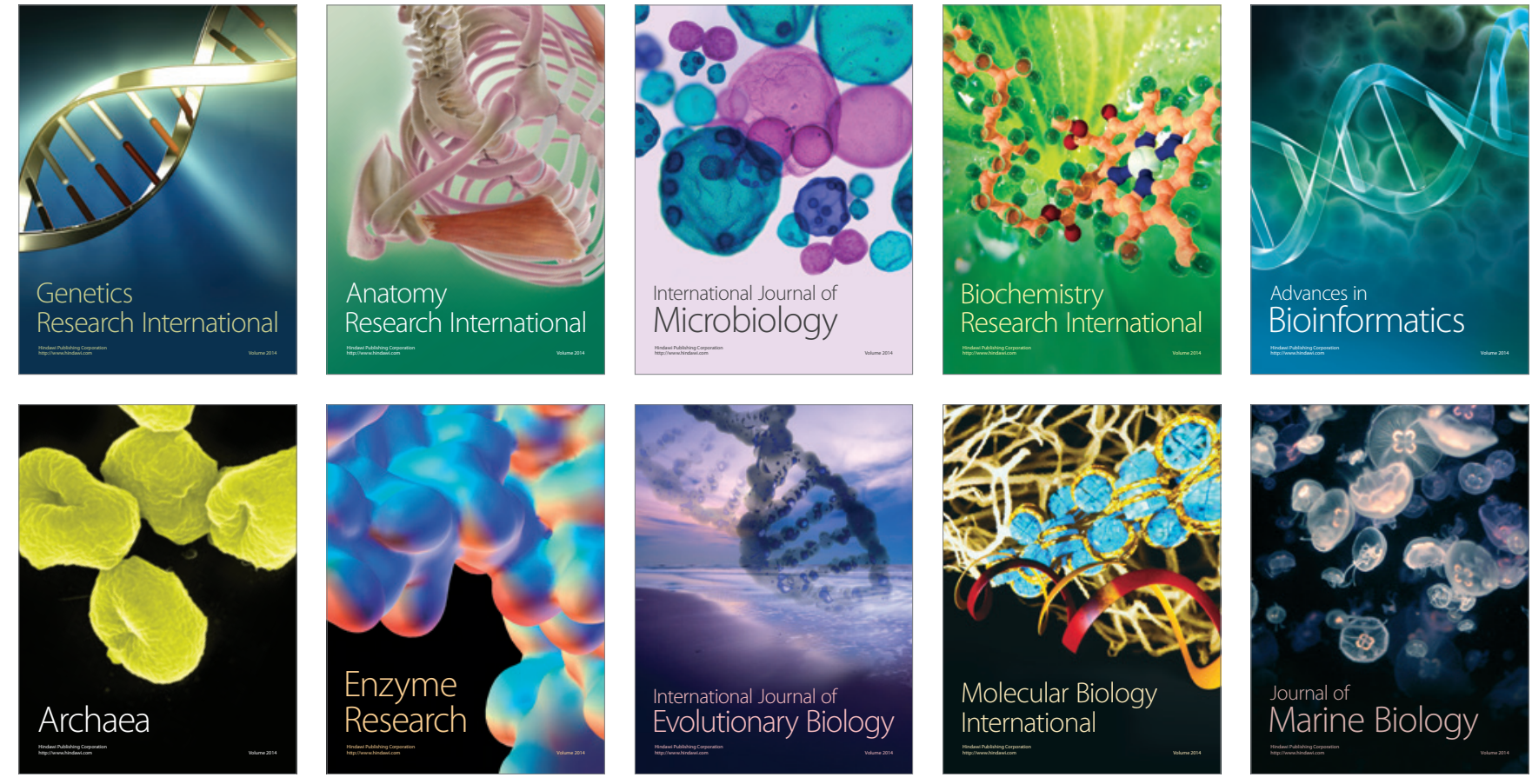